\title{
A Compact Flexible and Frequency Reconfigurable Antenna for Quintuple Applications
}

\author{
Mubashir Ul HASSAN ${ }^{1}$, Farzana ARSHAD ${ }^{1}$, Syeda Iffat $N A Q V I^{1}$, Yasar AMIN ${ }^{1,2}$ \\ Hannu TENHUNEN ${ }^{2,3}$ \\ ${ }^{1}$ ACTSENA Research Group, University of Engineering and Technology (UET), Taxila, 47050, Pakistan \\ 2 iPack VINN Excellence Center, Royal Institute of Technology (KTH), SE-16440, Stockholm, Sweden \\ ${ }^{3}$ TUCS, University of Turku, Turku-20520, Finland
}

Farzana.arshad@uettaxila.edu.pk,mmubashirulhassan@gmail.com

Submitted March 10, 2017 / Accepted June 11, 2017

\begin{abstract}
A novel, compact coplanar waveguide-fed flexible antenna is presented. The proposed design uses flexible Rogers RT/duroid 5880 (0.508 mm thickness) as a substrate with small size of $30 \times 28.4 \mathrm{~mm}^{2}$. Two switches are integrated on the antenna surface to change the current distribution which consequently changes the resonance frequency under different conditions of switches, thereby making it a frequency reconfigurable antenna. The antenna design is simulated on $C S T^{\circledR} M W S^{\circledR}$. The proposed antenna exhibits $V S W R<2$ and appreciable radiation patterns with positive gain over desired frequency bands. Good agreement exists between simulated and measured results. On the basis of results, the proposed antenna is envisioned to be deployed for the following applications; aeronautical radio navigation $[4.3 \mathrm{GHz}]$, AMT fixed services [4.5 GHz], WLAN [5.2 GHz], Unlicensed WiMAX [5.8 $\mathrm{GHz}]$ and $X$-band [7.5 $\mathrm{GHz}]$.
\end{abstract}

\section{Keywords}

Flexible antennas, reconfigurable antenna, coplanar waveguide-fed, switches

\section{Introduction}

An antenna operating on multiple frequency bands has gained a lot of attention due to the proliferation of modern wireless technology and customer demand for multiple services in a single device. Conventionally, a frequency band is associated with a particular wireless service; therefore multi-band antenna is required to support multiple services in a single wireless device. Multi-band antennas can operate over different frequency bands exhibiting good gain and stable radiation pattern. Albeit, multiband antennas transmit electromagnetic waves simultaneously at all the supported frequencies in addition to the desired frequency. Also, electromagnetic radiations from the wireless device have an adverse effect on human health.
The reconfigurable antennas mitigate the above-mentioned problems associated with the multi-band antennas. Such type of antennas can be reconfigured at the desired frequency band, radiation pattern and polarization. Reconfiguration can be achieved by deploying switches within the radiating element of the antenna [1]. A reconfigurable antenna reduces interference from adjacent unused bands and minimizes the filter requirements of the front end circuits, thus making the design compact [2]. Frequency reconfigurable antenna with wide bandwidth is generally chosen because of its miniaturization, cost effectiveness and better tuning ability between different frequency bands without affecting the gain and stability of radiation pattern.

Frequency agility can be realized using different types of switches like varactor diodes [3], pin diodes [4], RF MEMS [5] and FET switches [6]. In [3], varactor diodes are used for reconfiguration, but varactor diodes are nonlinear and their continuous tuning range is narrow in nature [4]. Switching between multiple bands requires a large number of pin diodes that increases the insertion loss and complicates the biasing circuitry [7]. RF MEMS has a low loss, but its deployment is expensive [8]. In [9], three pin diodes are employed in U-shaped and L-shaped slots for LTE, AMT Fixed Services, and WLAN applications. However, it uses antenna element on both sides of the substrate. Microstrip based frequency and pattern reconfigurable antenna is reported in [10] that utilizes five pin diodes. It has three operating modes; omnidirectional at $2.4 \mathrm{GHz}$, unidirectional at $5.4 \mathrm{GHz}$ and both omnidirectional and unidirectional operating concurrently. In [11], frequency reconfigurable antenna using a thick substrate ( $3.3 \mathrm{~mm}$ thickness) is presented in which resonance is controlled by shorting strips; moreover, the conical radiation pattern is maintained even at higher frequencies. A compact frequency reconfigurable antenna proposed in [12] utilizes a simple square shaped radiating patch for Bluetooth, WLAN, and WiMAX applications. Three pin diodes are inserted in ground plane that controls switching bands. A novel frequency reconfigurable antenna using the FR4 substrate that switches between an ultra wide band, narrow band, and dual band mode is proposed in [13]. 
Switching is achieved by four pin diodes along with the slotted structure that is created on the ground. Microstrip based frequency reconfigurable antenna is proposed in [14]. Using five pin diodes it achieves six switchable bands from $2.2 \mathrm{GHz}$ to $4.75 \mathrm{GHz}$. However, the above-mentioned designs suffer from three main drawbacks; the first is their larger dimension, the second is limited impedance bandwidth, the third is design complexity in terms of numerous switches and intricate structure.

Nowadays, flexible antennas have gained much importance because of their low profile, light weight, and robustness [15]. Different flexible substrates have been reported in [15-18]. In [15], the crescent-shaped antenna is presented using flexible RO4003 Rogers with the impedance bandwidth of $7.1 \mathrm{GHz}$. Kapton ${ }^{\circledR}$ polyamide- based multi-band antenna is proposed in [16]. Paper-based antenna for $2.4 \mathrm{GHz}$ WLAN application is introduced in [17]. Dual frequency rejection at $5.25 \mathrm{GHz}$ and $5.775 \mathrm{GHz}$ is successfully achieved in [18] using flexible Liquid Crystal Polymer. Above-mentioned flexible antennas have nonreconfigurable functions. Various feeding techniques have been used in flexible antennas, but coplanar waveguide feeding is preferable as it reduces complication by placing an antenna element and a patch on the same side of the substrate. One pin diode is employed in the T-shaped antenna for WLAN and WiMAX applications. However, its gain is comparatively low and its fabrication is expensive [19].

In this paper, a novel compact, flexible and frequency reconfigurable antenna is proposed. Both features; flexibility, and reconfiguration are added in this design which makes it attractive for conformal and many other applications. Switches are employed to change the electrical length of the radiator which subsequently changes the resonant frequency. Thus, by applying switches at an appropriate location in the proposed design, frequency reconfiguration is possible for five different applications.

The main contributions of this paper are as follows:

- A novel, compact, flexible and frequency reconfigurable antenna is proposed for Aeronautical Radio Navigation (ARN), AMT fixed Services, WLAN, WiMAX and X-band applications.

- Useful frequency bands are achieved for every On/ Off state of the switches.

- Gain and bandwidth enhancement using the flexible substrate.

\section{Antenna Design and Reconfigura- tion}

The proposed design is shown in Fig. 1. The proposed antenna uses Flexible Rogers RT/Duroid 5880 as a substrate. The dielectric constant of the substrate is 2.2 and loss tangent is 0.0009 with the thickness of $0.508 \mathrm{~mm}$. The

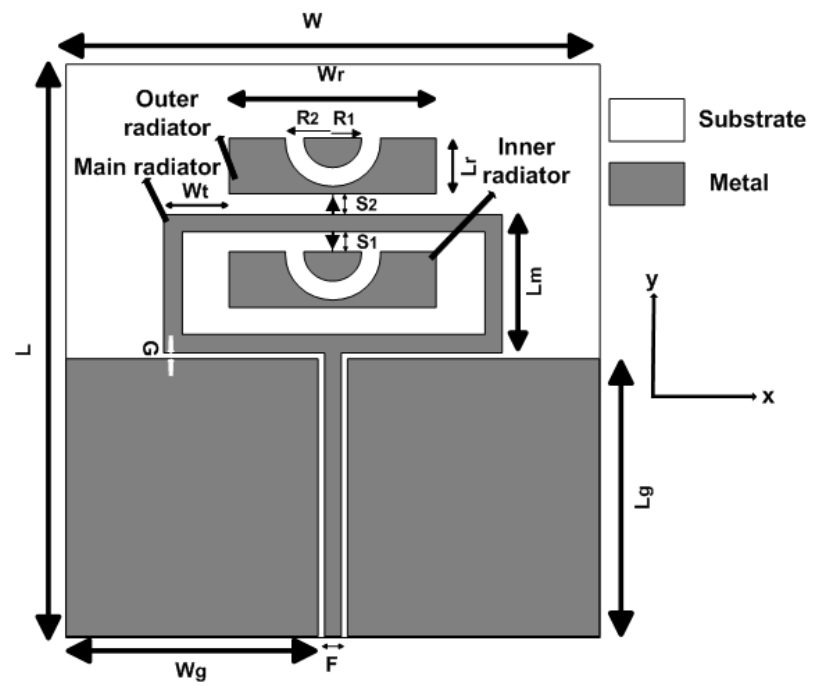

Fig. 1. Antenna configuration (top view).

\begin{tabular}{|c|c|c|c|}
\hline Parameter & Value (mm) & Parameter & Value (mm) \\
\hline $\mathrm{L}$ & 30 & $\mathrm{Lm}$ & 7.3 \\
\hline $\mathrm{W}$ & 28.4 & $\mathrm{Lr}$ & 3 \\
\hline $\mathrm{Lg}$ & 14.642 & $\mathrm{Wt}$ & 5.2 \\
\hline $\mathrm{Wg}$ & 13.45 & $\mathrm{Wr}$ & 11 \\
\hline $\mathrm{F}$ & 1 & $\mathrm{R} 1$ & 1.5 \\
\hline $\mathrm{G}$ & 0.358 & $\mathrm{R} 2$ & 2.5 \\
\hline
\end{tabular}

Tab. 1. Optimized parameters of the proposed design.

proposed antenna has a compact size of $30 \mathrm{~mm} \times 28.4 \mathrm{~mm}$. The antenna is fed by a $50 \Omega$ microstrip line.

The CPW feed line having the width of $1 \mathrm{~mm}$ is connected to the main radiator. The inner and outer radiator is connected to the main radiator via switch S1 and S2. First of all, CPW fed rectangular antenna which has a single band at $5.8 \mathrm{GHz}$ is designed. The rectangle is introduced inside and outside the main radiator to acquire more resonance frequencies. The arc-shaped slots are introduced in appropriate locations in the inner and outer rectangle to obtain the desired band. The width of slot controls the current intensity and minimizes the return loss. The lumped element boundary condition is used to implement the switches in $\mathrm{CST}^{\mathbb{B}} \mathrm{MWS}^{\mathbb{B}}$. With the four states of switches five resonance modes at $4.2 \mathrm{GHz}, 4.3 \mathrm{GHz}, 5.1 \mathrm{GHz}$, $5.8 \mathrm{GHz}$ and $7.5 \mathrm{GHz}$ are excited with good impedance matching. Different parameters are described in Tab. 1.

\section{Results and Discussion}

The prototype of the proposed antenna is fabricated and tested to validate the performance of the design. Measurements are taken using the Vector Network Analyzer (VNA) R\&S ZVL13.

The description of states ( 1 to 4 ) in terms of the position of the two switches is described in Tab. 2. The status of the switch, i.e. whether the switch is On/off actually defines the electrical length of the antenna structure that contributes for radiating a particular frequency band. S1 and S2 are the switches that are implemented using con- 
ductor/conducting wires between two conductors to provide the path. Although diodes can be used to provide the path, but this conductor is used because of limitations. When both S1 \& S2 are shorted simultaneously, the current circulates in the main radiator as well as in the inner and outer radiator. When both S1 and S2 are open, the current circulates only in the main radiator.

The simulated surface current distribution of the proposed antenna at various frequencies under different states of switches is shown in Fig. 2 (a-e). Figure 2(a) suggests that inner radiator radiates due to coupling with surrounding walls of the main radiator. The main radiator and the outer radiator also radiate. In this case, the current follows the longer path, hence antenna resonates at a low frequency of $4.2 \mathrm{GHz}$ with an impedance bandwidth of $630 \mathrm{MHz}$ (3.9-4.53 GHz) that covers $4.3 \mathrm{GHz}$ Aeronautical Radio Navigation. Figure 2(b) indicates that due to strong current intensity around S1 and S2 another frequency band from $7.2 \mathrm{GHz}$ to $7.8 \mathrm{GHz}$ with an impedance bandwidth of $600 \mathrm{MHz}$ is also observed in state 1 . It is noticed that in state 2 the antenna covers the frequency range of (4.7$5.4 \mathrm{GHz}$ ) with an impedance bandwidth of $700 \mathrm{MHz}$ that covers $5.2 \mathrm{GHz}$ WLAN. The impedance bandwidth in state 3 is $700 \mathrm{MHz}(3.9-4.6 \mathrm{GHz})$ that is sufficient for the standard of $4.5 \mathrm{GHz}$ AMT Fixed Services. In state 4, the only main radiator is contributing to the radiation, hence, current follows the shortest path so, resonance at $5.5 \mathrm{GHz}$ with a very wide bandwidth of $1 \mathrm{GHz}(5-6 \mathrm{GHz})$ is achieved. It covers $5.5 \mathrm{GHz}$ WLAN and $5.8 \mathrm{GHz}$ unlicensed WiMAX. As mentioned earlier that single rectangular antenna operates at $5.8 \mathrm{GHz}$. Therefore, the shift in frequency from $5.8 \mathrm{GHz}$ to $5.5 \mathrm{GHz}$ is due to the presence of strong coupling that exists in the gap between the main radiator, arc-shaped radiators as well as around the switches.

The prototype of the proposed antenna is illustrated in Fig. 3. Input reflection coefficient, VSWR, gain and radiation patterns are discussed in this section. Figure 4 shows the simulated and measured reflection coefficient of the proposed antenna for different states of switches. The measured $\mathrm{S}_{11}$ response is in accordance with the simulated results. However, the slight shift between simulated and measured frequencies is due to fabrication inaccuracy, but it still covers the desired frequency bands. It has been observed that bandwidth for $4.2 \mathrm{GHz}, 7.5 \mathrm{GHz}, 4.3 \mathrm{GHz}$, $5.1 \mathrm{GHz}$ and $5.5 \mathrm{GHz}$ band is $18 \%, 8 \%, 16.2 \%, 13.7 \%$ and $18.18 \%$, respectively. Figures 5 and 6 show that $V S W R<2$ has been successfully achieved at required resonance bands.

\begin{tabular}{|c|c|c|c|c|}
\hline States & S1 & S2 & $\begin{array}{c}\text { Frequency } \\
\text { (GHz) }\end{array}$ & $\begin{array}{c}\text { Bandwidth } \\
\text { (MHz) }\end{array}$ \\
\hline State 1 & ON & ON & $4.2 \& 7.5$ & $630 \& 600$ \\
\hline State 2 & ON & OFF & 5.1 & 700 \\
\hline State 3 & OFF & ON & 4.3 & 700 \\
\hline State 4 & OFF & OFF & 5.5 & 1000 \\
\hline
\end{tabular}

Tab. 2. Configuration of switches.

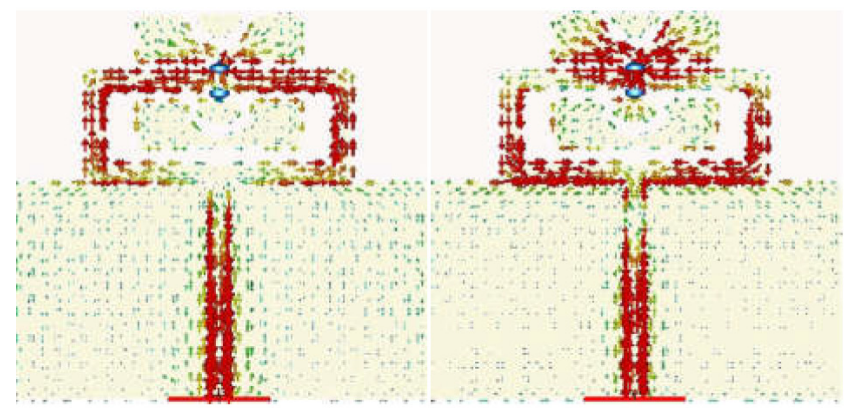

(a)

(b)

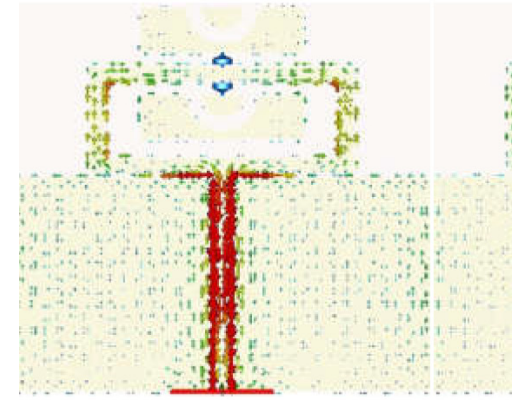

(c)

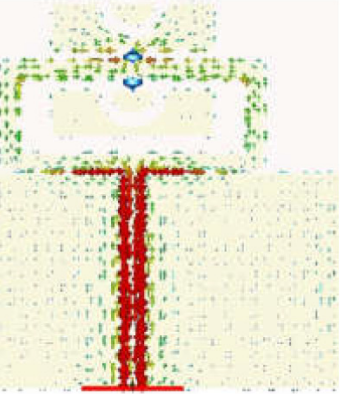

(d)

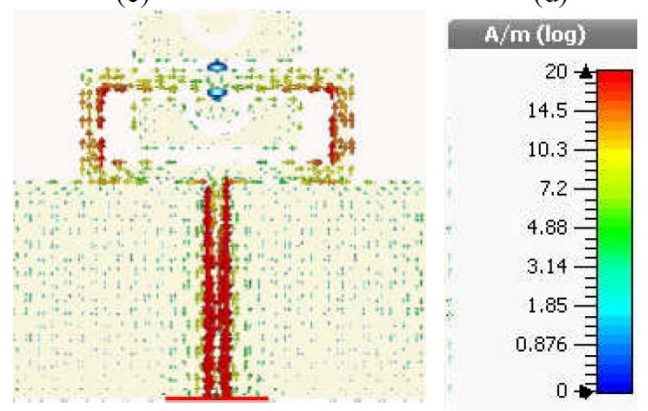

(e)

Fig. 2. Current distribution: (a) $4.2 \mathrm{GHz}$ at state 1 , (b) $7.5 \mathrm{GHz}$ at state 1, (c) $5.1 \mathrm{GHz}$ at state 2, (d) $4.3 \mathrm{GHz}$ at state 3 , (e) $5.5 \mathrm{GHz}$ at state 4 .

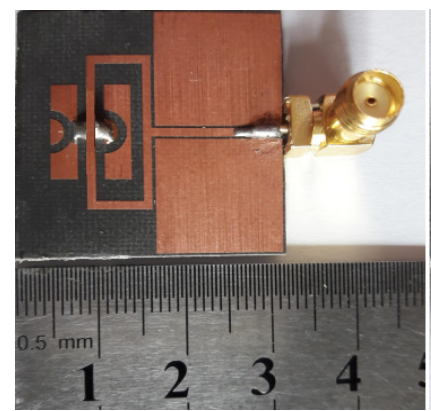

(a)

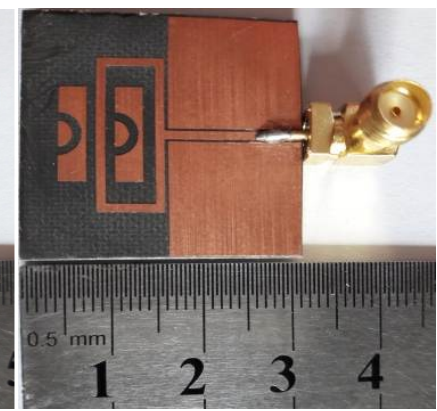

(b)
Fig. 3. The photograph of the fabricated antenna: (a) without switches (b) with switches.

The computed and measured gain of the proposed antenna in different states is shown in Fig. 7. The gain is computed at discrete frequencies that are of particular interest. The gain requirement is fulfilled in our proposed antenna as compared to [2], [19]. In [2], pin diode diminishes the gain and efficiency of the bow-tie antenna because of insertion loss introduced by the resistance diodes. 


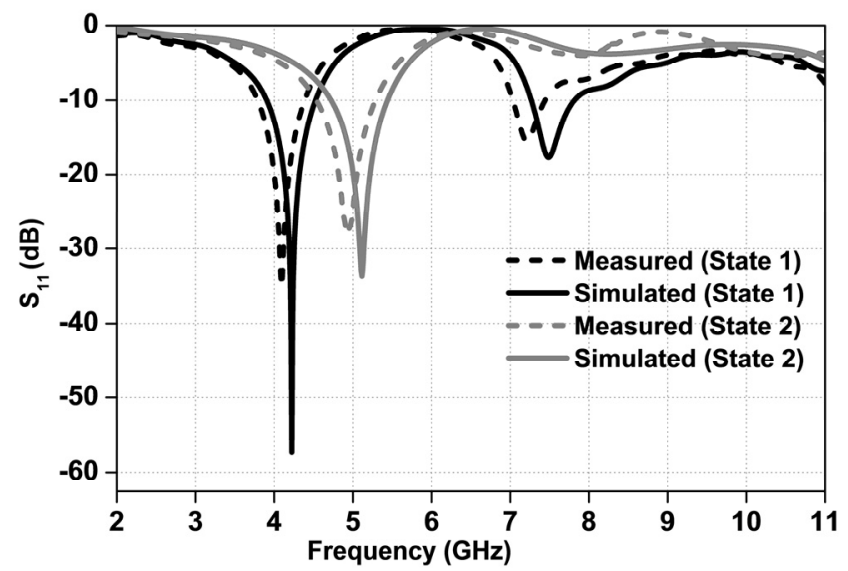

(a)

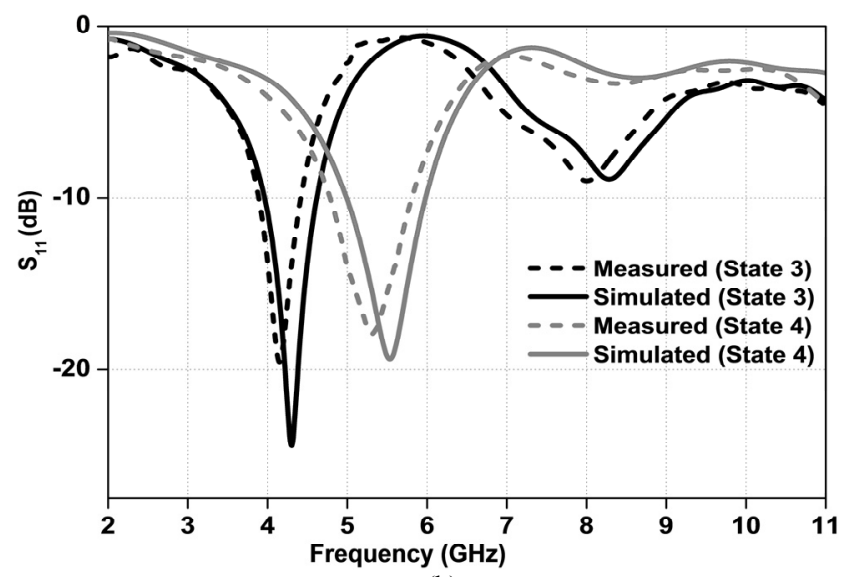

(b)

Fig. 4. Simulated and measured reflection coefficient for states (1-4).

Table 3 summarizes the gain comparison of the proposed antenna. Mostly literature does not mention radiation efficiency, although it is an important parameter for the reconfigurable antennas [20]. Due to reconfiguration techniques, radiation efficiency is emulated for such type of antennas. In the proposed work, radiation efficiency, greater than $90 \%$ is successfully achieved at required bands except for $7.5 \mathrm{GHz}$ where radiation efficiency is $74 \%$. (The radiation efficiency at $4.2 \mathrm{GHz}, 4.3 \mathrm{GHz}, \quad 5.1 \mathrm{GHz}$, $5.5 \mathrm{GHz}$ and $7.5 \mathrm{GHz}$ is $94.8 \%, 95.3 \%, 98.83 \%, 97.4 \%$

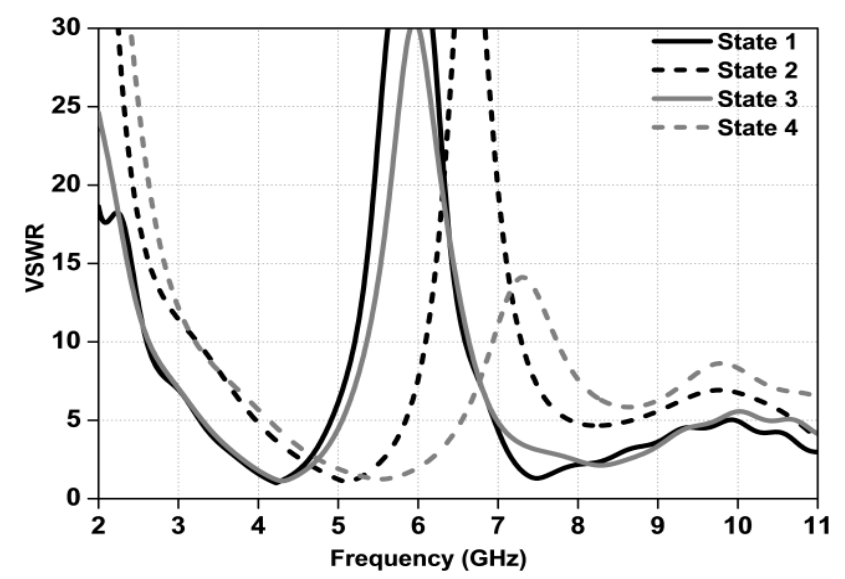

Fig. 5. Simulated VSWR.

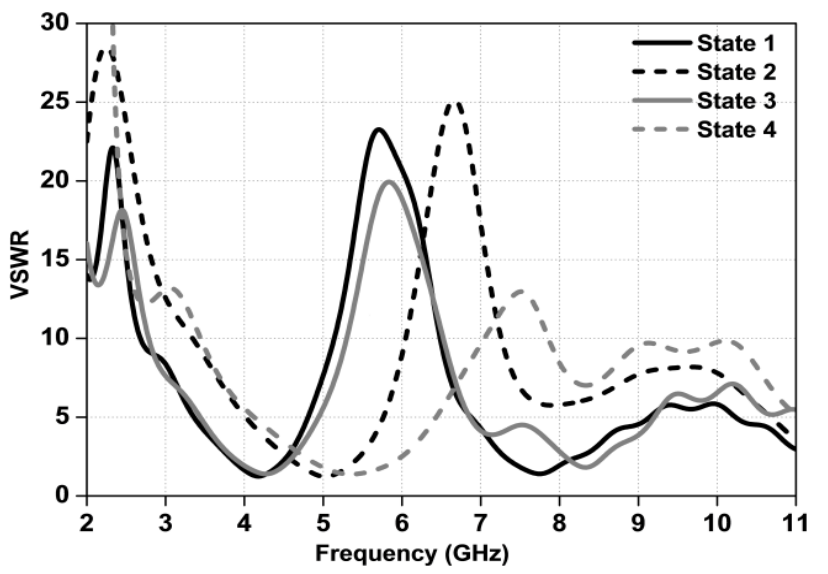

Fig. 6. Measured VSWR.

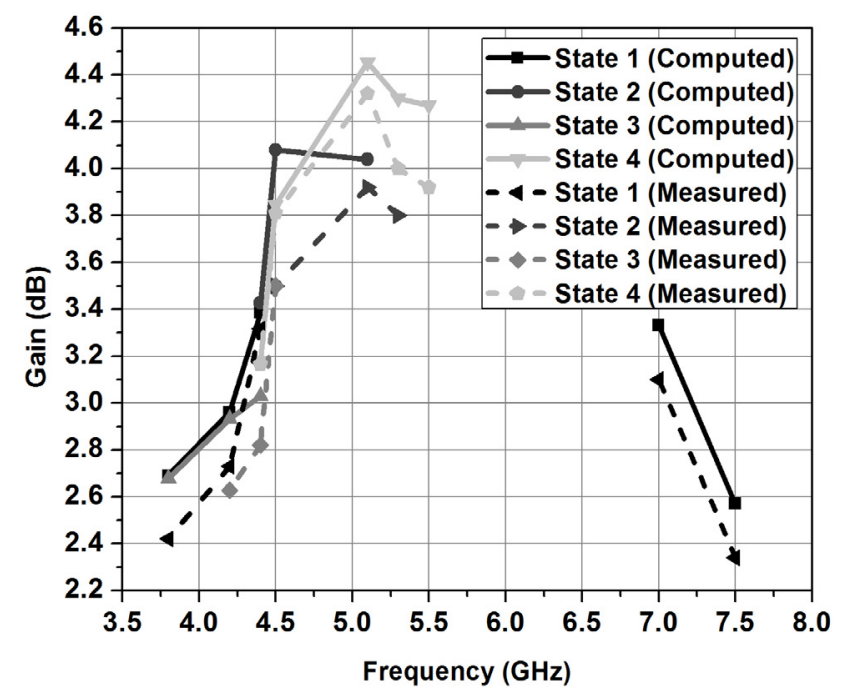

Fig. 7. Computed and measured gain (1-4).

\begin{tabular}{|l|l|l|l|l|l|}
\hline Frequency & $4.2 \mathbf{~ G H z}$ & $4.3 \mathbf{~ G H z}$ & $\mathbf{5 . 1} \mathbf{~ G H z}$ & $\mathbf{5 . 5} \mathbf{~ G H z}$ & $\mathbf{7 . 5} \mathbf{~ G H z}$ \\
\hline $\begin{array}{l}\text { Simulated } \\
\text { Gain (dB) }\end{array}$ & 2.96 & 2.98 & 4.04 & 4.27 & 2.57 \\
\hline $\begin{array}{l}\text { Measured } \\
\text { Gain (dB) }\end{array}$ & 2.73 & 2.72 & 3.92 & 3.92 & 2.34 \\
\hline
\end{tabular}

Tab. 3. Gain comparison of the proposed antenna.

and $74.6 \%$, respectively.) This is comparable to the radiation efficiency of a conventional dipole.

Figure 8 exhibits the simulated and measured radiation patterns in $\mathrm{E}$ and $\mathrm{H}$-planes at $4.2 \mathrm{GHz}, 4.3 \mathrm{GHz}$, $5.1 \mathrm{GHz}, 5.5 \mathrm{GHz}$ and $7.5 \mathrm{GHz}$. From Fig. 8, it can be concluded that the proposed antenna exhibits the good omnidirectional pattern in the H-plane and bidirectional pattern in the E-Plane. This shows that the antenna is apposite for integration with portable devices.

The proposed antenna is compared with few recently published works; the brief comparison is presented in Tab. 4. Table 4 shows that [9], [12], [14] uses relatively thick substrates. Also, their bandwidth is less compared to the proposed work. Although [10] has the bandwidth greater than $500 \mathrm{MHz}$ at three bands, but it employs five 
switches and achieves just four resonance bands. In [19], a very thin flexible substrate is used, but the bandwidth is even less than $300 \mathrm{MHz}$ in all the three resonance bands. It can be concluded that the proposed antenna has small size and shows better performance in terms of impedance bandwidth.

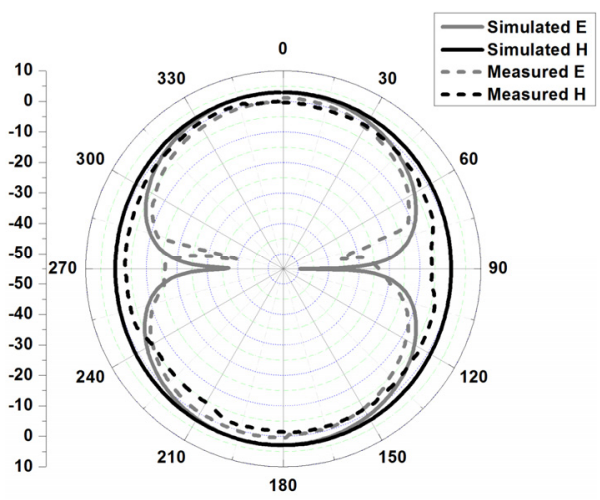

(a)

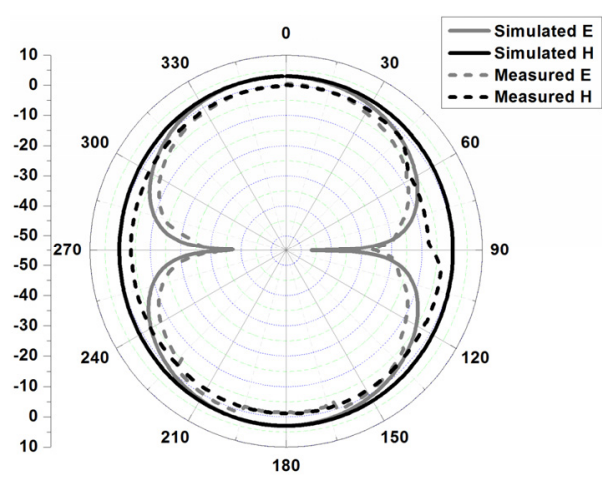

(c)

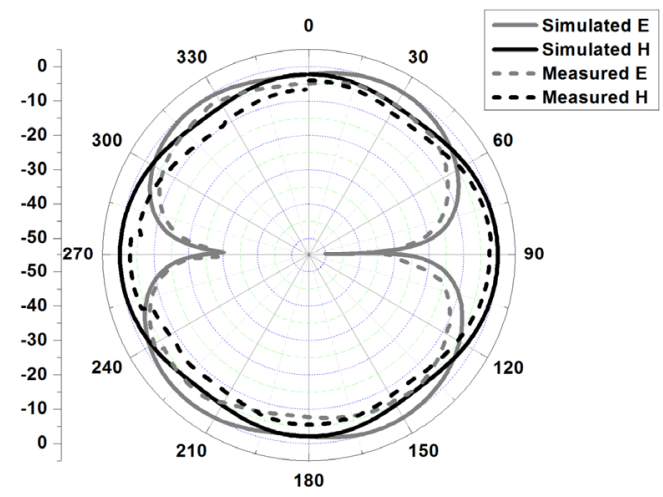

(b)

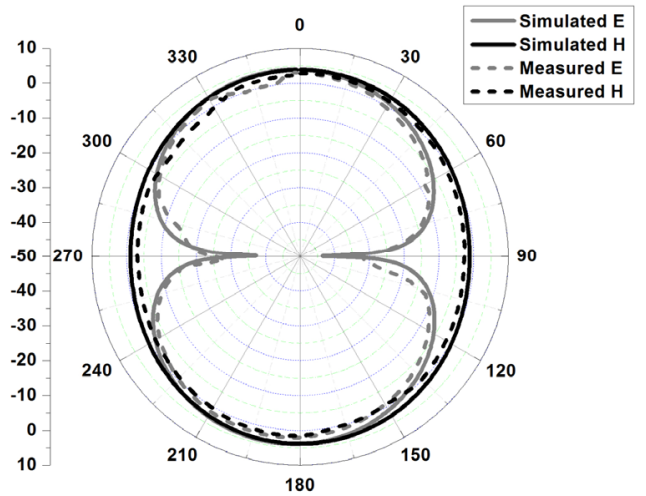

(d)

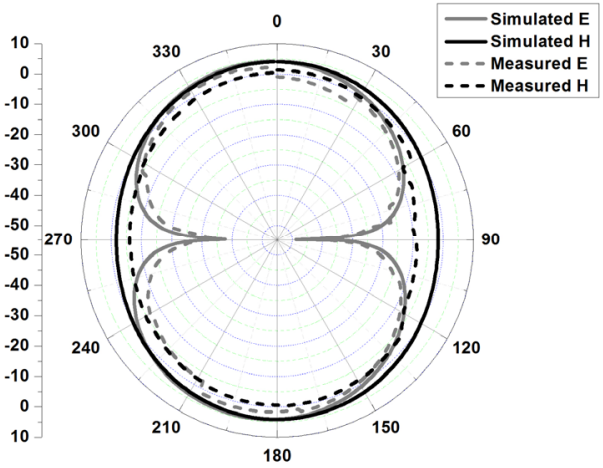

(e)

Fig. 8. Simulated and measured radiation patterns: (a) $4.2 \mathrm{GHz}$, (b) $7.5 \mathrm{GHz}$, (c) $5.1 \mathrm{GHz}$, (d) $4.3 \mathrm{GHz}$, (e) $5.5 \mathrm{GHz}$.

\begin{tabular}{|c|c|c|c|c|c|c|}
\hline Characteristics & [9] & [10] & [12] & {$[14]$} & [19] & This work \\
\hline Area $\left(\mathrm{mm}^{2}\right)$ & 675 & 1852.3 & 400 & 2300 & 1829 & 852 \\
\hline Thickness(mm) & 0.8 & 1.5 & 0.8 & 1.52 & 0.1 & 0.508 \\
\hline Substrate & RO4350B & RO4350 & FR4 & Taconic RF35 & PET & RT 5880 \\
\hline No. of switches & 3 & 5 & 3 & 5 & 1 & 2 \\
\hline No. of resonances & 6 & 4 & 3 & 6 & 3 & 5 \\
\hline $\begin{array}{c}\text { Bandwidth at } \\
\text { different } \\
\text { resonance bands } \\
(\mathrm{MHz})\end{array}$ & $\begin{array}{c}100 ; 120 ; 280 \\
220 ; 100 ; 320\end{array}$ & $\begin{array}{c}690 ; 300 ; 740 \\
620\end{array}$ & $210 ; 400 ; 580$ & $\begin{array}{l}250 ; 310 ; 300 \\
300 ; 260 ; 210\end{array}$ & $160 ; 180 ; 270$ & $\begin{array}{c}630 ; 600 ; 700 \\
1000 ; 700\end{array}$ \\
\hline
\end{tabular}

Tab. 4. Comparison with previous work. 


\section{Conclusion}

A frequency reconfigurable antenna for Aeronautical Radio Navigation, AMT Fixed services, WLAN, unlicensed WiMAX and X-band applications is proposed. The effective electrical length of the antenna is changed by employing switches that provide the wide tunability of the operating bands. The simulated and measured results are in good agreement. The antenna operates efficaciously at desired bands and has good radiation patterns. Simplicity, compactness, reconfigurability and flexibility are some features that make it a promising candidate for wireless applications.

\section{Acknowledgments}

This work was financially supported by Vinnova (The Swedish Governmental Agency for Innovation Systems) and University of Engineering and Technology Taxila, Pakistan through the Vinn Excellence Centers program and ACTSENA research group funding, respectively.

\section{References}

[1] SHAH, S. S. A., KHAN, M. F., ULLAH, S., et al. Design and measurement of planar monopole antenna for multi-band wireless applications. IETE Journal of Research, 2017, vol. 63, no. 2, p. 194-204. DOI: 10.1080/03772063.2016.1261049

[2] LI, T., ZHAI, H., WANG, X., et al. Frequency-reconfigurable bow-tie antenna for Bluetooth, WiMAX, and WLAN applications. IEEE Antennas and Wireless Propagation Letters, 2015, vol. 14, p. 171-174. DOI: 10.1109/LAWP.2014.2359199

[3] GE, L., LUK, K. M. Frequency-reconfigurable low-profile circular monopolar patch antenna. IEEE Transactions on Antennas and Propagation, 2014, vol. 62, no. 7, p. 3443-3449. DOI: 10.1109/TAP.2014.2318077

[4] LI, T., ZHAI, H., LI, L. Frequency-reconfigurable bow-tie antenna with a wide tuning range. IEEE Antennas and Wireless Propagation Letters, 2014, vol. 13, p. 1549-1552. DOI: 10.1109/LAWP.2014.2344676

[5] CETINER, B. A., CRUSATS, G. R., JOFRE, L., et al. RF MEMS integrated frequency reconfigurable annular slot antenna. IEEE Transactions on Antennas and Propagation, 2010, vol. 58, no. 3, p. 626-632. DOI: 10.1109/TAP.2009.2039300

[6] YANG, X. L., LIN, J. C., CHEN, G., et al. Frequency reconfigurable antenna for wireless communications using $\mathrm{GaAs}$ FET switch. IEEE Antennas and Wireless Propagation Letters, 2015, vol. 14, p. 807-810. DOI: 10.1109/LAWP.2014.2380436

[7] BHELLAR, B., TAHIR, F. A. Frequency reconfigurable antenna for handheld wireless devices. IET Microwaves, Antennas \& Propagation, 2015, vol. 9, no. 13, p. 1412-1417. DOI: 10.1049/iet-map.2015.0199

[8] CHEN, G., YANG, X. L., WANG, Y. Dual-band frequencyreconfigurable folded slot antenna for wireless communications. IEEE Antennas and Wireless Propagation Letters, 2012, vol. 11, p. 1386-1389. DOI: 10.1109/LAWP.2012.2227293

[9] HAN, L., WANG, C., CHEN, X., et al. Compact frequencyreconfigurable slot antenna for wireless applications. IEEE
Antennas and Wireless Propagation Letters, 2016, vol. 15, p. 1795-1798. DOI: 10.1109/LAWP.2016.2536778

[10] LI, P. K., SHAO, Z. H., WANG, Q., et al. Frequency- and patternreconfigurable antenna for multi standard wireless applications. IEEE Antennas and Wireless Propagation Letters, 2015, vol. 14, p. 333-336. DOI: 10.1109/LAWP.2014.2359196

[11] ROW, J. S., LIN, T. Y. Frequency-reconfigurable coplanar patch antenna with conical radiation. IEEE Antennas and Wireless Propagation Letters, 2010, vol. 9, p. 1088-1091. DOI: 10.1109/LAWP.2010.2093118

[12] BORHANI, M., REZAEI, P., VALIZADE, A. Design of a reconfigurable miniaturized microstrip antenna for switchable multiband systems. IEEE Antennas and Wireless Propagation Letters, 2016, vol. 15, p. 822-825. DOI: 10.1109/LAWP.2015.2476363

[13] BOUDAGHI, H., AZARMANESH, M., MEHRANPOUR, M. A frequency-reconfigurable monopole antenna using switchable slotted ground structure. IEEE Antennas and Wireless Propagation Letters, 2012, vol. 11, p. 655-658. DOI: 10.1109/LAWP.2012.2204030

[14] MAJID, H. A., RAHIM, M. K. A., HAMID, M. R., et al. A compact frequency-reconfigurable narrowband microstrip slot antenna. IEEE Antennas and Wireless Propagation Letters, 2012, vol. 11, p. 616-619. DOI: 10.1109/LAWP.2012.2202869

[15] SAllaM, M. O., KANDIL, S. M., VOLSKI, V., et al. 2.4/5 GHz WLAN crescent antenna on flexible substrate. In 10th European Conference on Antennas and Propagation (EuCAP). Davos (Switzerland), 2016, p. 1-3. DOI: 10.1109/EuCAP.2016.7481498

[16] AHMED, S., TAHIR, F. A., SHAMIM, A., et al. A compact Kapton-based inkjet-printed multiband antenna for flexible wireless devices. IEEE Antennas and Wireless Propagation Letters, 2015, vol. 14, p. 1802-1805. DOI: 10.1109/LAWP.2015.2424681

[17] AnAgnostou, D. E., GHEethan, A. A., AMERT., et al. A direct-write printed antenna on paper-based organic substrate for flexible displays and WLAN applications. Journal of Display Technology, 2010, vol. 6, no. 11, p. 558-564. DOI: 10.1109/JDT.2010.2045474

[18] GHeEthan, A. A., Anagnostou, D. E. Dual band-reject UWB antenna with sharp rejection of narrow and closely-spaced bands. IEEE Transactions on Antennas and Propagation, 2012, vol. 60, no. 4, p. 2071-2076. DOI: 10.1109/TAP.2012.2186221

[19] SAEED, S. M., BALANIS, C. A., BIRTCHER, C. R. Inkjetprinted flexible reconfigurable antenna for conformal WLAN/WiMAX wireless devices. IEEE Antennas and Wireless Propagation Letters, 2016, vol. 15, p. 1979-1982. DOI: 10.1109/LAWP.2016.2547338

[20] DEL BARRIO, S. C., FOROOZANFARD, E., MORRIS, A., et al. Tunable handset antenna: Enhancing efficiency on TV white spaces. IEEE Transactions on Antennas and Propagation, 2017, vol. 65 , no. 4, p. 2106-2111. DOI: 10.1109/TAP.2017.2662221

\section{About the Authors...}

Mubashir UL HASSAN received his Bachelor's degree in Telecommunication Engineering from University of Engineering and Technology, Taxila in 2014. Currently, in the same University, he is enrolled as an MS Full time scholar. His research interests include planar antennas, multi-band and reconfigurable antennas.

Farzana ARSHAD has received her M.Sc. degree in Telecommunication Engineering from University of Engineer- 
ing and Technology, Taxila in 2010. Currently, she is an Assistant Professor at the Telecommunication Engineering Department and part time Ph.D. researcher of ACTSENA group, UET Taxila. Her research focuses on low profile multi-band and reconfigurable antenna design.

Syeda Iffat NAQVI received her M.Sc. degree in Telecommunication Engineering from University of Engineering and Technology Taxila, in 2011. Currently, she is an Assistant Professor at the Telecommunication Engineering Department and part time Ph.D. researcher of ACTSENA group, UET Taxila. Her research focuses on $\mathrm{RF}$ and microwave antenna designing for cutting edge wireless technologies.

Yasar AMIN is Chairman and Associate Professor of the Telecommunication Engineering Department, University of Engineering and Technology Taxila, Pakistan. $\mathrm{He}$ is founder of the ACTSENA Research Group at UET Taxila, Pakistan. He has done his B.Sc. in Electrical Engineering in 2001 with specialization in Telecommunication, and M.Sc. in Electrical Engineering in 2003 with specialization in System-on Chip Design from Royal Institute of Technology (KTH), Sweden. His Ph.D. is in Electronic and Computer Systems from Royal Institute of Technology (KTH), Sweden, with research focus on printable green RFID antennas for embedded sensors, while having an MBA in Innovation and Growth from Turku School of Economics, University of Turku, Finland. He has done several specialized courses from Stanford University, California, USA and Massachusetts Institute of Technology (MIT), USA. He has supervised over 15 M.Sc. thesis, and presently supervising 8 doctoral thesis. He is presently serving as leading Guest Editor at two international journals and an active reviewer of more than a dozen well reputed international journals. He has contributed to over 20 journal papers, over 30 reviewed international conference papers. Dr. Yasar is a member of IEEE, IET, ACM and ACES.

Hannu TENHUNEN is Chair Professor of Electronic Systems at Royal Institute of Technology (KTH), Stock- holm, Sweden. Prof. Tenhunen has held professor position as full professor, invited professor or visiting honorary professor in Finland (TUT, UTU), Sweden (KTH), USA (Cornel U), France (INPG), China (Fudan and Beijing Jiatong Universities), and Hong Kong (Chinese University of Hong Kong), and has an honorary doctorate from Tallinn Technical University. He has been director of multiple national large scale research programs or being an initiator and director of national or European graduate schools. He has actively contributed in VLSI and SoC design in Finland and Sweden via creating new educational programs and research directions, most lately at European level as being the EU-level Education Director of the new European flagship initiative European Institute of Technology and Innovations (EIT), and its Knowledge and Innovation Community EIT ICT Labs. Prof. Tenhunen has been active in promoting the innovation system and innovation support mechanism in research and education both at national and European level. Prof. Tenhunen has been a board member in science parks, startup companies, and has served as advisor or expert for high technology companies and venture capitalists, as well as evaluator for EU and national programs and research institutes. He has supervised over 70 M.Sc. thesis, 39 doctoral theses, and 8 post-doc. From his doctoral students and post-docs, as of today, 21 are currently professors and associate professors. Prof. Tenhunen has served on the Technical Program Committees of all major conferences in his area, have been general Chairman or vice-chairman or member of Steering Committee of multiple conferences in his core competence areas. He has been one of the founding editorial board members of 3 scientific journals, has been questing editor for multiple special issues of scientific journals or books, and has contributed numerous invited papers to journals. He has contributed to over 110 journal papers, over 625 reviewed international conference papers, over 170 nonreviewed papers, local conference papers, or other publications, and 9 international patents granted in multiple countries. Prof. Tenhunen is a member of the Academy of Engineering Science of Finland. 